\title{
Introduction to the Special Issue - a Personal Note
}

\author{
Alan W. Schwartz ${ }^{1}$ \\ Published online: 3 July 2017 \\ (C) Springer Science+Business Media B.V. 2017
}

I first met Jim Ferris in 1958, when I was a new graduate student at FSU and Jim was a new Assistant Professor who was engaged in natural products chemistry. I was hunting for chemistry faculty members to be members of my $\mathrm{PhD}$ committee and "natural products" seemed reasonably close to my interests of biochemistry and origin of life research. At a brief and friendly meeting Jim agreed to serve on the committee. Our paths soon (temporarily) diverged, however, when Jim left Tallahassee for The Salk Institute in San Diego, where he joined the group of Leslie Orgel. It was clearly in this period that Jim developed his interest in prebiotic chemistry, a theme which was to dominate the rest of his career. After joining RPI, he established a strong research program, obtaining major NASA funding and leading eventually to the establishment of a NASA Specialized Center of Research and Training (NSCORT) for the Study of Origins of Life in the Albany area of New York. This program continued until his retirement in 2015 and inspired an entire generation of graduate students and other colleagues. Jim was recognized in many ways for his contributions to research on the origin of life, including the award of ISSOL's highest honor; the Oparin Medal in 1996 and a special session in Jim's honor at the 2012 Astrobiology Science Conference. In 2012, RPI received a gift from the Emily Landecker Foundation to establish the James P. Ferris Fellowship in Astrobiology. Jim was the director of the NASA-funded New York Center for Studies on the Origins of Life from 1998 to 2006, President of ISSOL from 1993 to 1996 and Editor of this journal for 18 years. He will be fondly remembered by most of us. This issue of OLEB, with Sandra Pizzarello as guest Editor, contains papers which are dedicated to that memory.

Alan W. Schwartz

originseditor@outlook.com

1 Radboud University, Nijmegen, The Netherlands 